\title{
G2-S16 dendrimer microbicide does not interfere with the vaginal immune system
}

\author{
Alba Martín-Moreno ${ }^{1,2}$, Daniel Sepúlveda-Crespo ${ }^{1}$, Ma Jesús Serramía-Lobera ${ }^{1,2}$, Ana Judith Perisé-Barrios ${ }^{1}$ \\ and $\mathrm{M}^{a}$ Angeles Muñoz-Fernández ${ }^{1,2^{*}}$ (1)
}

\begin{abstract}
It is essential that prophylactic drugs do not interfere with the normal function of the immune system. The use of nanoparticles as vaginal microbicides is a promising prevention strategy against sexually transmitted infections. With that aim, our group is working with the G2-S16, a second generation carbosilane dendrimer with sulfonate groups in the periphery, which has been previously shown to be effective against HIV-1 and HSV-2 infection, and it is now on the road to clinical trials. Our objective in this new study is to assess the effects of G2-S16 on the immune barrier of the female reproductive tract. The expression of differentiation, maturation and activation markers was measured in epithelial cells, dendritic cells, M and GM macrophages, and T cells using RT-qPCR and flow cytometry. The results demonstrate that G2-S16 does not alter the natural immunity of the vagina, strongly supporting the biosafety of this dendrimer for clinical use.
\end{abstract}

Keywords: G2-S16 dendrimer, Microbicide, Immunity, Antigen presenting cells, Lymphocytes

\section{Background}

Vaginal microbicides offer a promising strategy in preventing sexual transmission of human immunodeficiency virus type 1 (HIV-1) and other genital tract infections $[1,2]$. The microbicides should not interfere in the ability of genital mucosa to provide protection against other pathogens. The cervicovaginal epithelial cells, dendritic cells (DCs), tissue-resident macrophages (MØs), and T-lymphocytes associated with the female reproductive tract (FRT) play a crucial role in the early recognition of pathogens and launching of an immune response against vaginal infections $[3,4]$.

The innate immune system constitutes the first line of defense against viral infection, especially after disruption of mucosal epithelium that occurs during sexual intercourse. The innate immune response leads to inflammation, recruitment of immune cells from the bloodstream

\footnotetext{
*Correspondence: mmunoz.hgugm@gmail.com; mmunoz.

hgugm@salud.madrid.org

1 Sección Inmunología, Laboratorio InmunoBiología Molecular,

Hospital General Universitario Gregorio Marañón (HGUGM), Instituto de Investigación Sanitaria Gregorio Marañón (IiSGM), and Spanish HIV-HGM BioBank, Madrid, Spain

Full list of author information is available at the end of the article
}

to tissue, and activation of adaptive immunity to specifically fight the infection [5]. Activation of the immune system is triggered when pathogen-associated molecular patters are recognized by pattern recognition molecules like Toll-like receptors (TLRs) on the host cells, remarkably epithelial cells, mucosal DCs, tissue MØs and mucosal resident T-cells [6]. As a result of TLRs stimulation, an inflammatory response is initiated after activation of several intracellular signaling pathways and the subsequent production of pro-inflammatory cytokines $[7,8]$. Ten different TLRs (TLR1-TLR10) have been identified in humans $[9,10]$, and each one of them specifically recognizes different antigens [11].

Dendritic cells are cells of the innate immune system, but their role as antigen presenting cells (APCs) makes them a link between the innate and the adaptive immune system. DCs are sentinels that capture and process antigens, mature and migrate to secondary lymphoid tissues where they present the antigens and activate T-cells.

Also working as APCs are the MØs. MØs secrete cytokines that recruit the rest of the immune cells to sites of infection [12], and orchestrate the immune response. $\mathrm{M} \emptyset \mathrm{s}$ are classified as pro-inflammatory [M1 or GM-CSF-polarized MØs (GM-MØs)] or 
anti-inflammatory [M2 or M-CSF-polarized MØs (M-MØs)]. GM-MØs are phagocytic cells that eliminate pathogens, infected or cancerous cells, or cell debris, and clean the tissues, while secreting proinflammatory cytokines and thus contributing to tissue destruction. On the other hand, M-MØs activate T-cell system, secrete anti-inflammatory cytokines and promote tissue regeneration. Hence, a correct balance of GM/M-MØs maintains homeostasis, whereas disequilibrium can induce chronic inflammation and disease [13].

It is necessary for any microbicide not only to prevent infection but also not to interfere with the function of the immune cells. Nanotechnology is being widely used in the design of novel systems as microbicides capable of disrupting HIV transmission [14, 15]. Polyanionic carbosilane dendrimer G2-S16 has emerged as a promising potential microbicide. G2-S16 (see Fig. 1 for details about the dendrimer) belongs to a heterogeneous group of compounds acting as HIV/herpes simplex virus-type 2 (HSV-2) entry inhibitors that have shown to be harmless and effective in different in vitro and in vivo models [16-20]. G2-S16 is currently on the road to clinical trials, but in order to further guarantee the safety of its use as vaginal gel, we here tested the effect of this dendrimer on cell viability, TLR expression and differentiation, maturation and activation of the main immune cells localized in the vaginal mucosa. Our

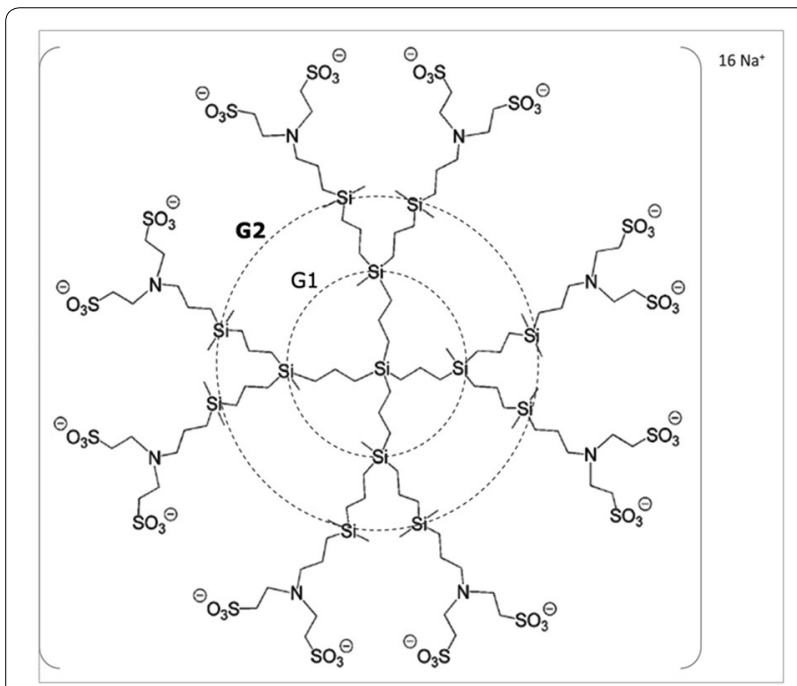

Fig. 1 Chemical structure of second-generation polyanionic carbosilane dendrimer G2-S16. The generation were defined as the number of repeated layers of silicon atoms forming the dendrimer. The capping layer consists of 16 sulfonate groups (-SO3-). The molecular formula is $\mathrm{C} 112 \mathrm{H} 244 \mathrm{~N} 8 \mathrm{Na} 16 \mathrm{O} 48 \mathrm{~S} 16 \mathrm{Si} 13$ and the molecular weight is $3717.15 \mathrm{~g} / \mathrm{mol}$ results clearly show that G2-S16 does not interfere with the normal function of the mucosal barrier, and vaginal innate or adaptive immunity.

\section{Results \\ Cytotoxicity of G2-S16 dendrimer on dendritic cells and monocyte-derived macrophages}

We selected $10 \mu \mathrm{M}$ as the in vitro working concentration for G2-S16 in epithelial VK2/E6E7 cells, peripheral blood mononuclear cells (PBMCs) and purified T-cells as determined in previous published studies $[19,21]$. However, the cytotoxicity of G2-S16 on DCs or MØs had not been evaluated. Thus, DCs and MØs were treated for $48 \mathrm{~h}$ with increasing concentrations of G2-S16 dendrimer $(1-50 \mu \mathrm{M})$ that were considered toxic when the survival rate was $<80 \%$. DMEM medium and 20\% dimethyl sulfoxide (DMSO; Sigma) were used as non-treated and cell death controls, respectively. G2-S16 was non-toxic at a concentration of $1 \mu \mathrm{M}$ on iDCs (Fig. 2a) and of $5 \mu \mathrm{M}$ on mDCs (Fig. 2b) whereas was considered non-toxic up to $10 \mu \mathrm{M}$ on GM-MØs (Fig. 2c). G2-S16 was non-toxic over the full range of concentrations assayed on M-MØs (up to $50 \mu \mathrm{M}$; Fig. 2d). Thus, the selected non-toxic working concentrations for the following in vitro assays were of $1 \mu \mathrm{M}$ in DCs and $10 \mu \mathrm{M}$ in MØs.

\section{Toll-like receptor expression in vaginal epithelial cells remains unaffected in the presence of G2-S16 dendrimer} The epithelium is the first line of defense against potential pathogens or harming substances, and, although frequently underestimated, it is a key component of the immune system. It has been observed that activation of TLRs in the epithelial cells induces inflammatory responses and the disruption of tight junctions, increasing mucosal permeability and facilitating microbe infiltration [22]. In order to test the safety of G2-S16 as vaginally-applied microbicide, we used TaqmanRT-qPCR to evaluated the change in expression of TLR1-10 in human vaginal epithelial cell line VK2/E6E7 exposed to G2-S16 $(10 \mu \mathrm{M})$ versus nontreated VK2/E6E7 cells for short ( $3 \mathrm{~h})$, medium $(6 \mathrm{~h})$ or long $(18 \mathrm{~h})$ times. cDNA was amplified using the specific PCR forward and reverse primer pairs described in Table 1. A peak in TLR2 expression was observed at $6 \mathrm{~h}(p<0.05)$, but the expression was back to basal levels by the $18 \mathrm{~h}$ time-point (Fig. 3). Exposure to G2-S16 did not modify the expression of any other TLR from TLR1 to TLR6 in VK2/E6E7 cells. mRNA expression of TLR7-10 in VK2/E6E7 cells was undetectable by RTPCR. These results strongly suggest that the immune function of the vaginal epithelium is not affected after exposure of our G2-S16 dendrimer. 

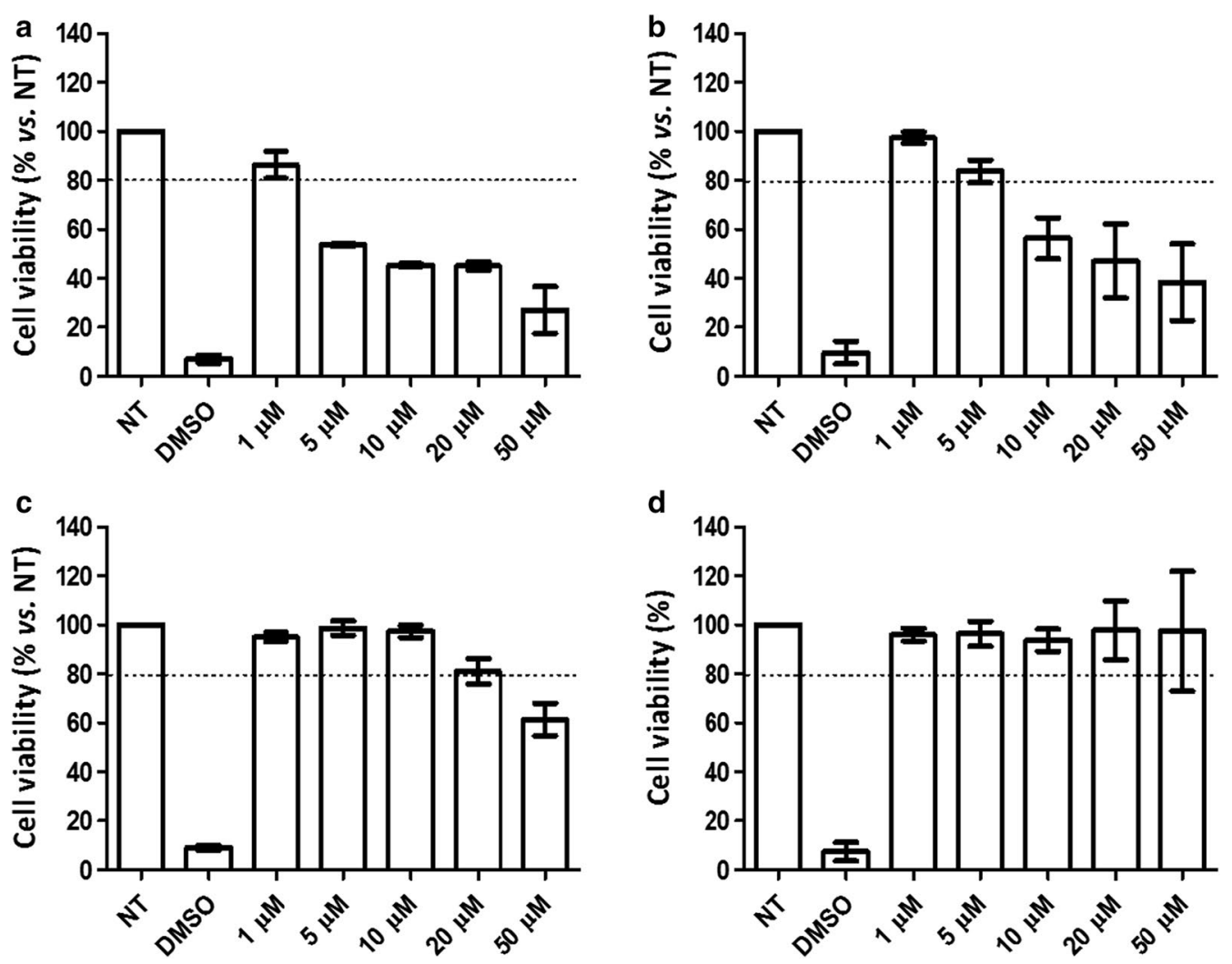

Fig. 2 Cytotoxicity associated to G2-S16 in dendritic cells and macrophages. a iDCs, $\mathbf{b}$ mDCs, c GM-M Øs or $\mathbf{d}$ M-M $\varnothing$ s were loaded with increased concentrations of G2-S16 (ranged from 1 to $50 \mathrm{\mu M}$ ) or treated with 20\% of DMSO (control of cell death) for $48 \mathrm{~h}$. The percent of cell viability was calculated by MTT as optical density of treated condition/non-treated control (NT) $\times 100$. The $80 \%$ of viability was set as limit of toxicity. Data are represented as mean \pm SD of three experiments performed in triplicate. DMSO: dymethyl sulfoxide; iDCs: immature dendritic cells; mDCs: mature dendritic cells; GM-MØs: pro-inflammatory or M1 macrophages; M-MØs: anti-inflammatory or M2 macrophages

Table 1 Real time PCR primer pairs used for quantification of human TLR mRNA

\begin{tabular}{llll}
\hline TLR & Forward primer & Reverse primer & $\begin{array}{c}\text { Amplicon } \\
\text { size (bp) }\end{array}$ \\
\hline LR1 & GGTCTTGCTGGTCTTAGGAGAGAC & CTGAAGTCCAGCTGACCCTGTAGCTTCACG & 372 \\
TLR2 & GGCCAGCAAATTACCTGTGTG & CTGAGCCTCGTCCATGGGCCACTCC & 637 \\
TLR3 & CGGGCCAGCTTTCAGGAACCTG & GGCATGAATTATATATGCTGC & 400 \\
TLR4 & TGCAATGGATCAAGGACCAGAGGC & GTGCTGGGACACCACAACAATCACC & 449 \\
TLR5 & CCTCATGACCATCCTCACAGTCAC & GGCTTCAAGGCACCAGCCATCTC & 355 \\
TLR6 & CCAAGTGAACATATCAGTTAATACTTTAGGGTGC & CTCAGAAACACGGTGACAAAGCTG & 358 \\
TLR7 & CTCCCTGGATCTGTACACCTGTGAG & CTCCCACAGAGCCTTTTCCGGGCT & 551 \\
TLR8 & GTCCTGGGGTCAAAGAGGGAAGAG & CTCTTACAGATCCGCTGCCGTAGCC & 581 \\
TLR9 & GCGAGATGAGGATGCCCTGCCCTACG & TTCGGCCGTGGGTCCCTGGCAGAAG & 510 \\
TLR10 & CAGAGGTCATGATGGTTGGATGG & GACCTAGCATCCTGAGATACCAGGGCAG & 256 \\
\hline
\end{tabular}

G2-S16 dendrimer does not alter expression of TLR in monocyte-derived macrophages, but increases expression of TLR2 and TLR7 in iDCs

The next line of defense behind the vaginal epithelium is formed by tissue-resident cells of the innate immune system, especially DCs and MØs. Both cells types recognize pathogens through TLRs, whose activation launches a signaling cascade that derives in expression of pro-inflammatory cytokines, cell maturation and proliferation, and consequent activation of the 

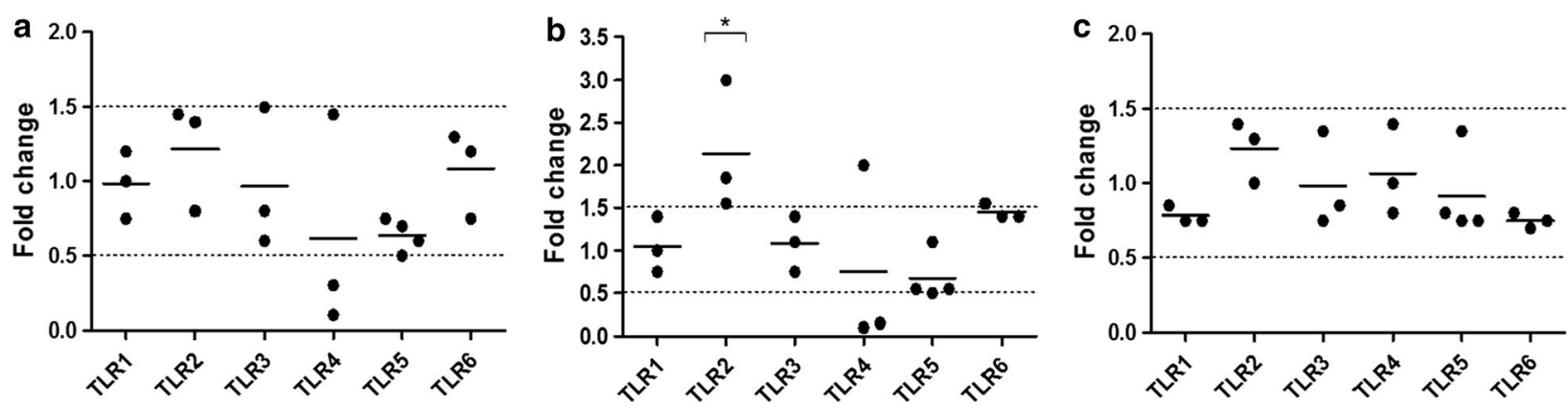

Fig. 3 Quantification of TLR gene expression on treated VK2/E6E7. TLR1-10 mRNA expression was determined by RT-qPCR in VK2/E6E7 cells treated with G2-S16 (10 $\mu \mathrm{M})$ for $\mathbf{a} 3 \mathrm{~h}, \mathbf{b} 6 \mathrm{~h}$ and $\mathbf{c} 18 \mathrm{~h}$. Insufficient detection of certain TLR mRNA expression levels by RT-PCR was not included here to simplify the representation. Data shows relative mRNA levels; analyzed gene was normalized to TATA box binding protein expression (TBP) and referred to non-treated cells. Individual values (dots) and mean (bar) of at least three independent experiments are shown. Dashed lines indicate threshold values

immune response. To examine the modulation of the TLR expression in these cell types by G2-S16, we measured the mRNA expression of TLR1-10 in iDCs, and monocyte-derived M-MØs and GM-MØs after treatment with G2-S16 (at $1 \mu \mathrm{M}$ and $10 \mu \mathrm{M}$, respectively) for short $(3 \mathrm{~h})$, medium $(6 \mathrm{~h})$ or long $(18 \mathrm{~h})$ times. Expression of TLR3-5, 9 and 10 in iDCs, and TLR3, 9 and 10 in M-MØs and GM-MØs was under the detection limits of the RT-qPCR. In M-MØs and GM-MØs, no significant differences were observed in TLR1,2,4-8 expression after treatment with G2-S16 (Fig. 4a-f). This suggests that G2-S16 dendrimer does not cause a basal activation or alteration in $\mathrm{M} \varnothing$ function.

Interestingly, G2-S16 significantly up-regulated TLR2 (2-3-fold; $p<0.001)$ and TLR7 (2-7-fold; $p<0.001)$ at all studied times (Fig. $4 \mathrm{~g}-\mathrm{i}$ ). Previous studies showed that TLR2 engagement depends on its expression [23], and leads to DC activation [24], and production and release of IL-12 [25]. Similarly, TLR7 initiates a signaling cascade leading to DC maturation, and in the case of plasmacitoid DCs, it causes a release of type-I IFN. Our results suggested that G2-S16 dendrimer could be causing DC activation, leading to the following assays to make sure that the increase in TLR expression caused by the G2-S16, does not cause an unwanted DC maturation.

\section{G2-S16 does not affect the maturation of dendritic cells}

DCs are antigen-presenting cells that play a crucial role during the initiation and regulation of both innate and adaptive immunity. iDCs reside in peripheral tissues and are sentinels that capture antigen particles via TLR receptor, which leads to their activation. Upon activation, iDCs undergo maturation and migrate towards the draining lymph node, where $\mathrm{mDCs}$ expressing increased levels of co-stimulatory molecules, produce cytokines and interact with naive T-cell, initiating primary T-cell-mediated immune responses [26]. Therefore, the observed over-expression of TLR2 and TLR7 induced by exposure to G2-S16 could influence their phenotype and their ability to mature, thus impairing their function, or cause a basal DC maturation and consequent chronic inflammation. We examined the maturation of the DCs after G2-S16 dendrimer exposure in vitro.

First, we isolated $\mathrm{CD} 14^{+}$monocytes from PBMCs by magnetic-activated cell sorting using CD14 microbeads. The $\mathrm{CD} 14^{+}$monocytes were then differentiated into iDCs by cultivation with GM-CSF and IL-4 for 5 days. To produce $\mathrm{mDCs}$, iDCs were treated with LPS for 2 days, while the iDCs were maintained by addition of fresh GMCSF and IL-4. G2-S16 was added at the same time and kept for $48 \mathrm{~h}$ during maturation. We then compared the expression of surface markers CD14, CD1a, CD80, CD83 and CD86 in iDCs or mDCs. G2-S16 did not affect the expression of CD14 and CD1a, a type $1 \mathrm{CD} 1$ membrane protein widely used as human DCs markers expressed early in their development (Fig. 5) [27]. As shown in the Fig. 5, iDCs exhibited a similar immature phenotype when treated with G2-S16 compared to non-treated iDCs, although CD80 surface marker showed slight increase, but these results were not significant. Addition of LPS to iDCs induced high levels of expression of costimulatory molecules CD83, CD80 and CD86, comparable to what has been published in previous studies [28]. In the presence of G2-S16, DCs treated with LPS also presented a significant increase on maturation markers mDCs (CD80, CD83 and CD86), although slightly lower compared to non-treated mDCs (Fig. 5). Summarizing, G2-S16 did not induce significant changes in CD83, CD80 and CD86 expression levels in iDCs or mDCs, which suggests that the increased expression in TLR2 and TLR7 does not affect to the DC function. 

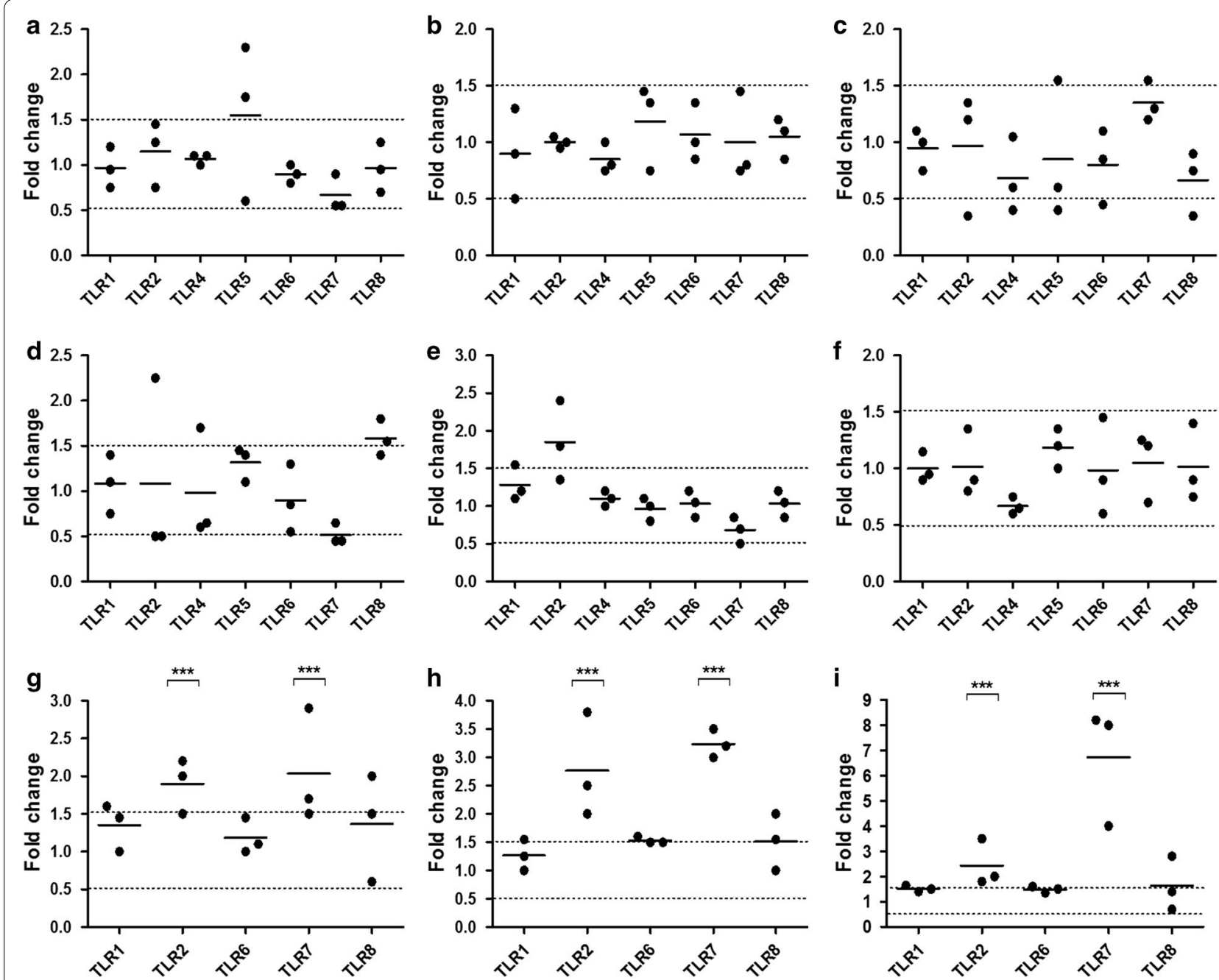

Fig. 4 Quantification of gene expression on treated iDCs M-MФs and GM-MФs. TLR1-10 mRNA expression was determined by RT-qPCR in a-c M-macrophages (M-MФs), d-f GM-macrophages (GM-MФs) or $\mathbf{g}$-i immature dendritic cells (iDCs) treated with G2-S16 (1 $\mu \mathrm{M}$ for iDCs and $10 \mu \mathrm{M}$ for M- and GM-MФs) for $\mathbf{a}, \mathbf{d}, \mathbf{g} 3 \mathbf{h}, \mathbf{b}, \mathbf{e}, \mathbf{h} 6 \mathbf{h}$ and $\mathbf{c}, \mathbf{f}, \mathbf{i} 18 \mathrm{~h}$. Insufficient detection of certain TLR mRNA expression levels by RT-PCR was not included here to simplify the representation. Data shows relative mRNA levels; analyzed gene was normalized to TATA box binding protein expression (TBP) and referred to non-treated cells. Individual values (dots) and mean (bar) of at least three independent experiments are shown. Dashed lines indicate threshold values

Migration of DCs from the site of HIV capture to the secondary lymphoid organs where they can act in association with T-cells is crucial for initiation of primary immune responses. DCs maturation and migration is correlated with an up-regulation of the chemokine receptor CCR7, in such a way that a decrease of CCR7 and its ligands leads to impaired DC migration into lymph nodes and lymphatic architectural abnormalities in peripheral tissues [29]. Therefore, we evaluated whether migration of $\mathrm{mDCs}$ could be altered in the presence of G2-S16. iDCs were obtained as previously explained and were then treated with G2-S16 $(1 \mu \mathrm{M})$ during maturation. Migration of DCs was evaluated by the expression of surface marker CCR7. The mDCs treated with G2-S16 have a similar ability to migrate compared to the migratory ability of non-treated mDCs (Fig. 5).

\section{G2-S16 dendrimer does not impede the differentiation from monocytes to M-MØs and GM-MØs and does not affect the phenotype of $M \emptyset s$}

MØs are tissue resident phagocytic cells that, together with DCs, constitute the first line of immune cells in the vagina. MØs can be divided in two populations, pro-inflammatory and microbicidal (GM-MØs) or immunosuppressant and tissue repairers (M-MØs). This populations are specially interesting during HIV 

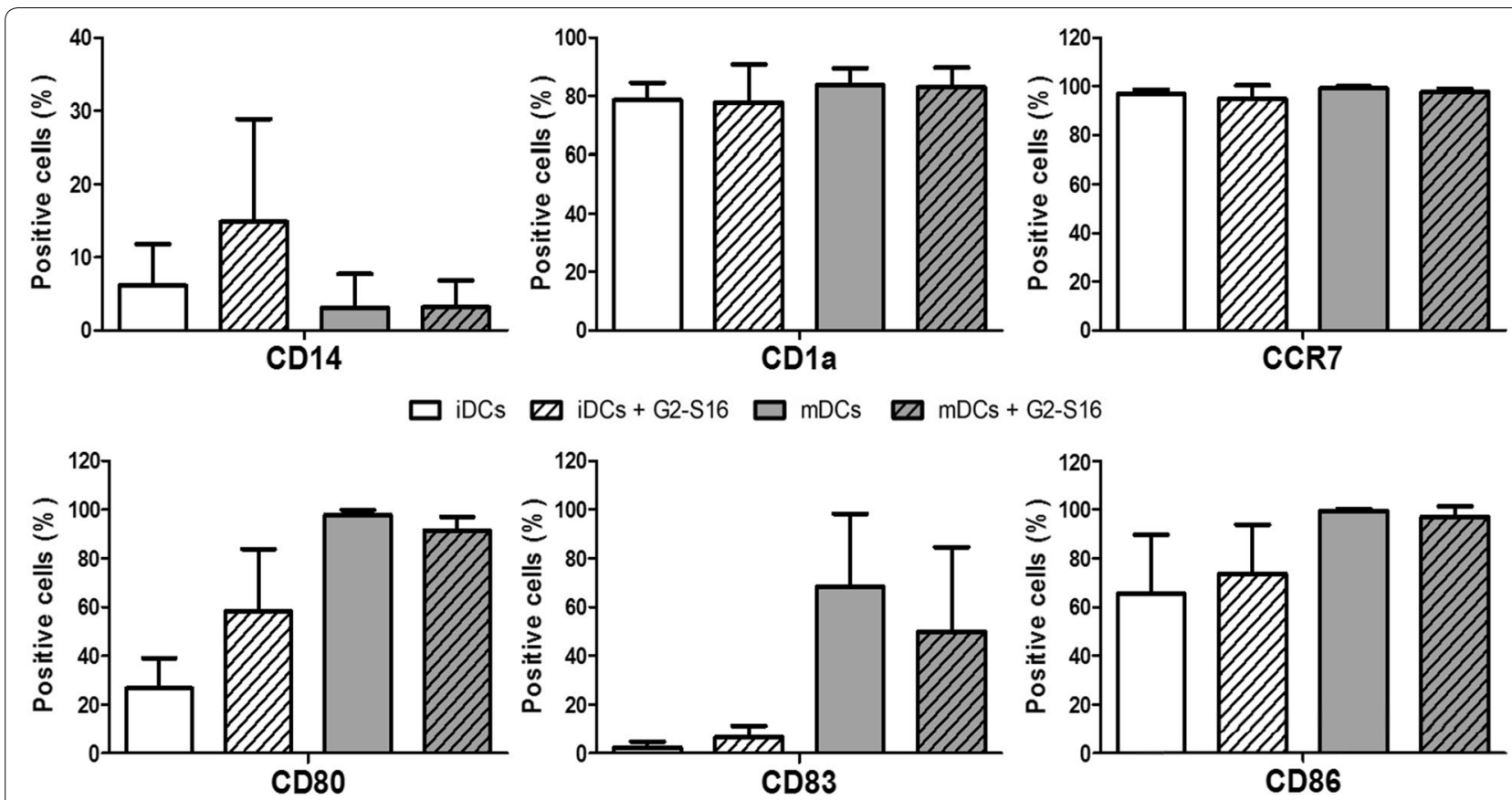

Fig. 5 Effect of G2-S16 on maturation of DCs. iDCs were treated with G2-S16 with and without LPA. After $48 \mathrm{~h}$, cells were stained with fluorescent antibodies against CD14, CD1a, CCR7, CD80, CD83 and CD86. DC marker expression was measured by flow cytometry. No significant difference was found between G2-S16 treated and untreated cells

pathogenesis as the virus takes advantage of their interchangeable polarization [30]. GM and M-MØs have mechanisms to block HIV-1 replication at different steps; GM-MØs inhibit genome integration, while M-MØs inhibit replication at a post-integration stage. HIV-1 fights this by transforming M-MØs into a GM-MØ-like phenotype, thus being able to complete the replication cycle in MØs [31], and blocking this change could result in an effective prophylactic treatment. However, it must be kept in mind that an unbalanced polarization is negative to the host due to tissue damage. Therefore, we evaluated whether G2-S16 affects the differentiation from monocytes to M-MØs and GM-MØs or whether G2-S16 could cause any change in phenotype, thus altering the physiological balance.

First, we isolated $\mathrm{CD} 14^{+}$monocytes from PBMCs by magnetic-activated cell sorting using CD14 microbeads. The $\mathrm{CD}_{1}{ }^{+}$monocytes were then differentiated into MØs by incubation with either GM-CSF or M-CSF for 7 days in the presence of G2-S16 $(10 \mu \mathrm{M})$ to evaluate the effect of the dendrimer on $M \varnothing$ differentiation. CD36 is a multi-ligand scavenger receptor related to phagocytosis which has been used to identify monocytes and MØs [32]. CD163 and CD209 (also known as DCSIGN) are highly expressed by M-MØs and in a lesser extent on GM-MØs [33, 34]. Fluorescence-activated cell sorting (FACS) analysis showed that G2-S16 did not modified he expression of monocyte surface markers and did not block the increased expression of the $M \varnothing$ markers, CD36, CD163 and CD209 (Fig. 6a), suggesting that G2-S16 does not affect the monocyte-M $\varnothing$ differentiation. These results are consistent with the fact that G2-S16 does not modify the expression of TLRs.

Once differentiated the MØs in the tissue, they can switch their phenotype between GM-MØs and M-MØs due to interaction with HIV-1 or other STIs pathogens. Therefore, we differentiated MØs according to the abovementioned protocol and evaluated whether G2-S16 could cause any changes or alter the physiological balance (Fig. 6b). We treated both lineages with G2-S16 for $48 \mathrm{~h}$. FACS analysis showed that G2-S16 did not alter the expression of CD14, CD36, CD163 or CD209 in GM-MØs or M-MØs, suggesting that G2-S16 is safe to respect the $M \varnothing$ balance.

\section{G2-S16 dendrimer does not modify the populations of $\mathrm{CD}^{+}$and $\mathrm{CD}^{+} \mathrm{T}$ cells or their expression of CCR5 and CXCR4}

Lymphocytes are part of the adaptive immune cells, and although they are cells of the adaptive immune system and are not usually considered part of the first line of defense, they are also infiltrated in the FRT, and detect pathogens that get in the tissue, including HIV-1, early in the process of infection. We studied whether G2-S16 
a
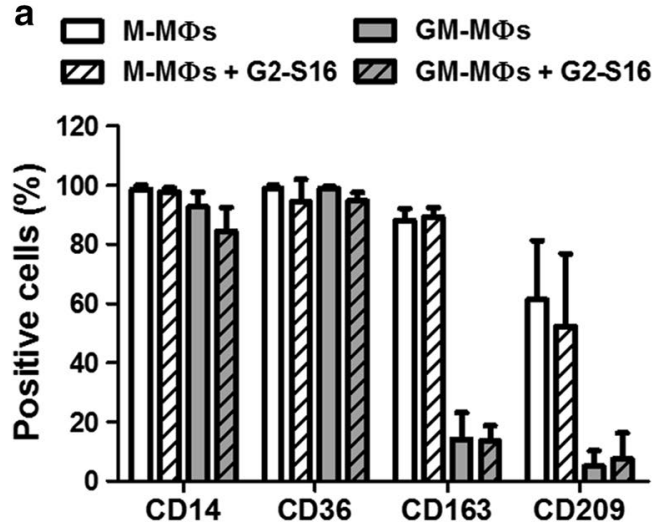

b $\square$ M-MФ $\square$ GM-MФ

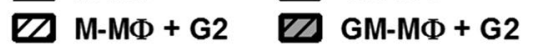

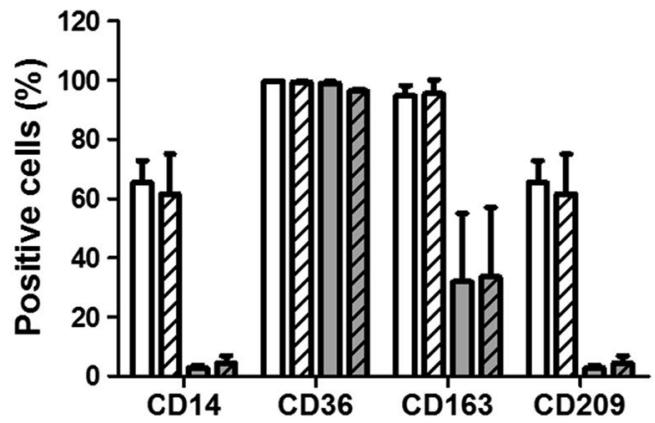

Fig. 6 Effect of G2-S16 on the differentiation from monocytes to macrophages and on the phenotype of differentiated M-M Øs and GM-M Øs. MØs were differentiated from peripheral blood monocytes into $M$ and GM-MØs. The cells were treated with G2-S16 (10 $\mu M)$ (a) during the differentiation process or (b) for $48 \mathrm{~h}$ after differentiation. MØs marker expression (CD14, CD36, CD163, CD209) was measured by flow cytometry. No significant difference was found between G2-S16 treated and untreated cells

modifies the populations of $\mathrm{CD}^{+}$and $\mathrm{CD}^{+} \mathrm{T}$ cells. We had previously shown that G2-S16 $(10 \mu \mathrm{M})$ inhibits HIV-1 infection in PBMCs, and now we demonstrate that this protective effect is not due to an alteration on the CD4 receptor. PHA-activated or non-activated PBMCs were treated with G2-S16 $(10 \mu \mathrm{M})$ for $48 \mathrm{~h}$ and then the surface proteins on $\mathrm{CD}^{+}$lymphocytes were measured by flow cytometry. No significant differences were observed in the binding of the anti-CD4 and anti-CD8 antibodies to the CD4 and CD8 cellular receptors. These results show that G2-S16 does not modify the percentage of CD4 or CD8 positive T cells, neither in basal state nor in PHA-activated PBMCs (Fig. 7a). A comparison of the mean fluorescence intensity (MFI) was used to verify that the amount of antibody bound, and thus, of protein expressed per cell was also not altered by G2-S16 dendrimer (Fig. 7b).

We also studied the expression of the HIV-1 co-receptors CCR5 and CXCR4 in the G2-S16 treated PBMCs. The experiment was performed in the same conditions, but antibodies against CCR5 and CXCR4 were used for flow cytometry. No significant difference was observed on the number of cells expressing the co-receptors after exposure to the G2-S16 dendrimer (Fig. 7c, e). The amount of protein exposed in the cell surface was also not altered after exposure to G2-S16, as shown by the comparison of the (MFI) (Fig. 7d, f).

Toll-like receptor expression in CD4-T cells remains unaltered in the presence of G2-S16 dendrimer

Although TLRs are primarily believed to dictate the innate immune response, increasing data is providing evidence of role of the expression and activation of TLRs in $\mathrm{T}$ cells, and thus, the adaptive immune response [35, 36]. We evaluated the expression of TLR1-10 in CD4 $4^{+} \mathrm{T}$ cells after treatment with G2-S16 $(10 \mu \mathrm{M})$ for short $(3 \mathrm{~h})$, medium $(6 \mathrm{~h})$ or long $(18 \mathrm{~h})$ times (Fig. 8). We used the forward and reverse primer pairs described in Table 1, and TLR1, 2, 6 and 8 were expressed at a detectable amount. TLR1 showed a slight increase (over 1.5 folds) at $6 \mathrm{~h}$ (Fig. 8b) and $18 \mathrm{~h}$ (Fig. 8c), but the difference was not statistically significant. Altogether, these data suggest that G2-S16 dendrimer does not have a significant effect on the expression of TLRs in $\mathrm{CD} 4^{+} \mathrm{T}$ cells at the time points studied.

\section{G2-S16 dendrimer does not modify the activation state of T-cells}

The previous results altogether suggest that G2-S16 does not activate the immune system, as it does not cause any maturation changes in the APCs and does not activate $T$ cells via TLR signaling either. To further prove that the adaptive immune cells are not altered by the dendrimer, we evaluated the expression of activation markers in PBMCs. Upon T-cell activation, several cell surface markers are up-regulated at different stages of the activation process. We chose CD69 are early activation marker, and HLA-DR as late activation marker [37]. PBMCs were treated with G2-S16 $(10 \mu \mathrm{M})$ for $48 \mathrm{~h}$ and the levels of surface markers on $\mathrm{CD}^{+}$lymphocytes were then measured by flow cytometry. No significant changes were observed on activation markers after treatment with G2-S16 compared to non-treated controls (Fig. 9) in $\mathrm{CD}^{+} \mathrm{CD}^{+}$or $\mathrm{CD}^{+} \mathrm{CD}^{+}$cells. Consistently with the previous assays, these results indicated that G2-S16 


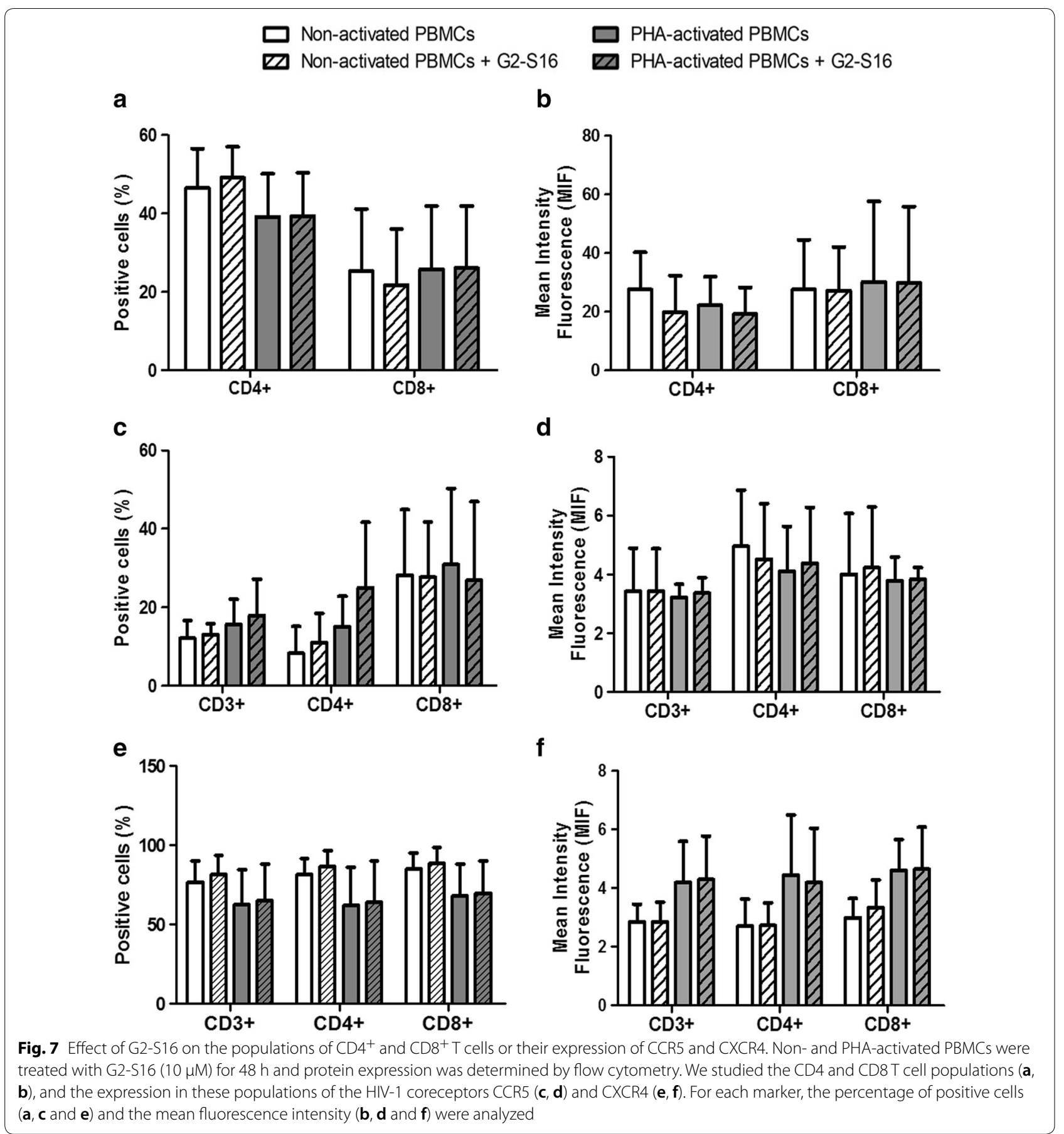

dendrimer does not affect the activation of the immune cells in the absence of an exogenous antigen.

\section{G2-S16 does not modify the population or activation state of $B$ cells}

$B$ cells are the lymphocytes responsible for the mucosal antibody defense. In order to evaluate whether G2-S16 affects the $\mathrm{B}$ cell population, we treated PBMCs with
G2-S16 $(10 \mu \mathrm{M})$ for $48 \mathrm{~h}$ and measured the B cell population by flow cytometry as $\mathrm{CD}^{-} \mathrm{CD}^{-} 9^{+}$cells, both in non-activated and IL-4-CD40L activated PBMCs. We observed no significant difference in the percentage of $B$ cells with or without treatment with the dendrimer (Fig. 10a).

We also studied the activation of the B cells under the same conditions. With that objective, we measured the 

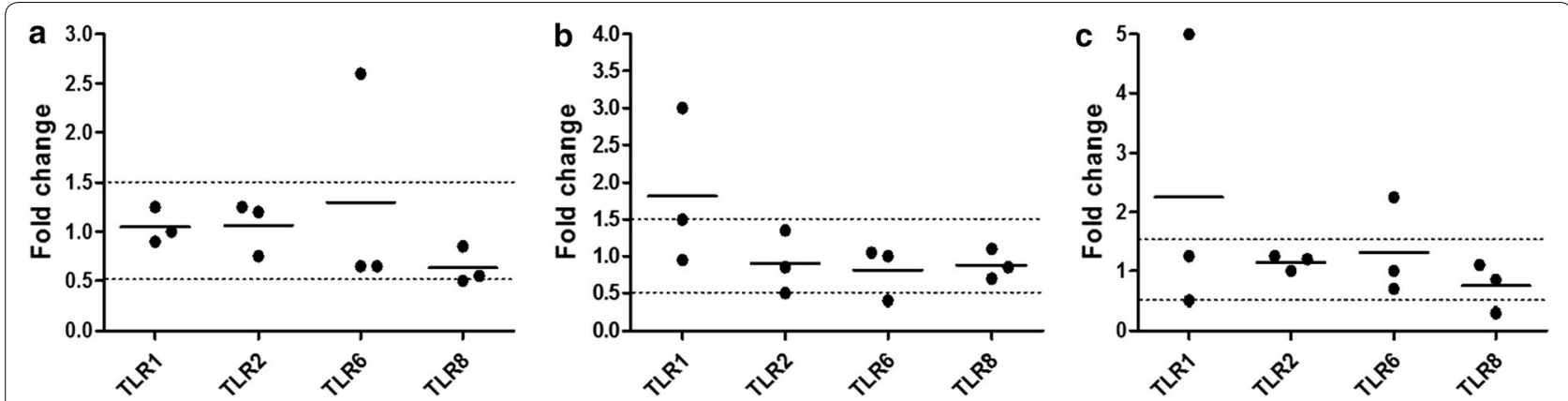

Fig. 8 Quantification of gene expression on treated CD4-T cells by real time RT-qPCR. TLR1-10 mRNA expression was determined by RT-qPCR in CD4-T cells treated with G2-S16 (10 $\mu$ M) for $\mathbf{a} 3 \mathrm{~h}, \mathbf{b} 6 \mathrm{~h}$ and $\mathbf{c} 18 \mathrm{~h}$. Insufficient detection of certain TLR mRNA expression levels by RT-PCR was not included here to simplify the representation. Data shows relative mRNA levels; analyzed gene was normalized to TATA box binding protein expression (TBP) and referred to non-treated cells. Individual values (dots) and mean (bar) of at least three independent experiments are shown. Dashed lines indicate threshold values

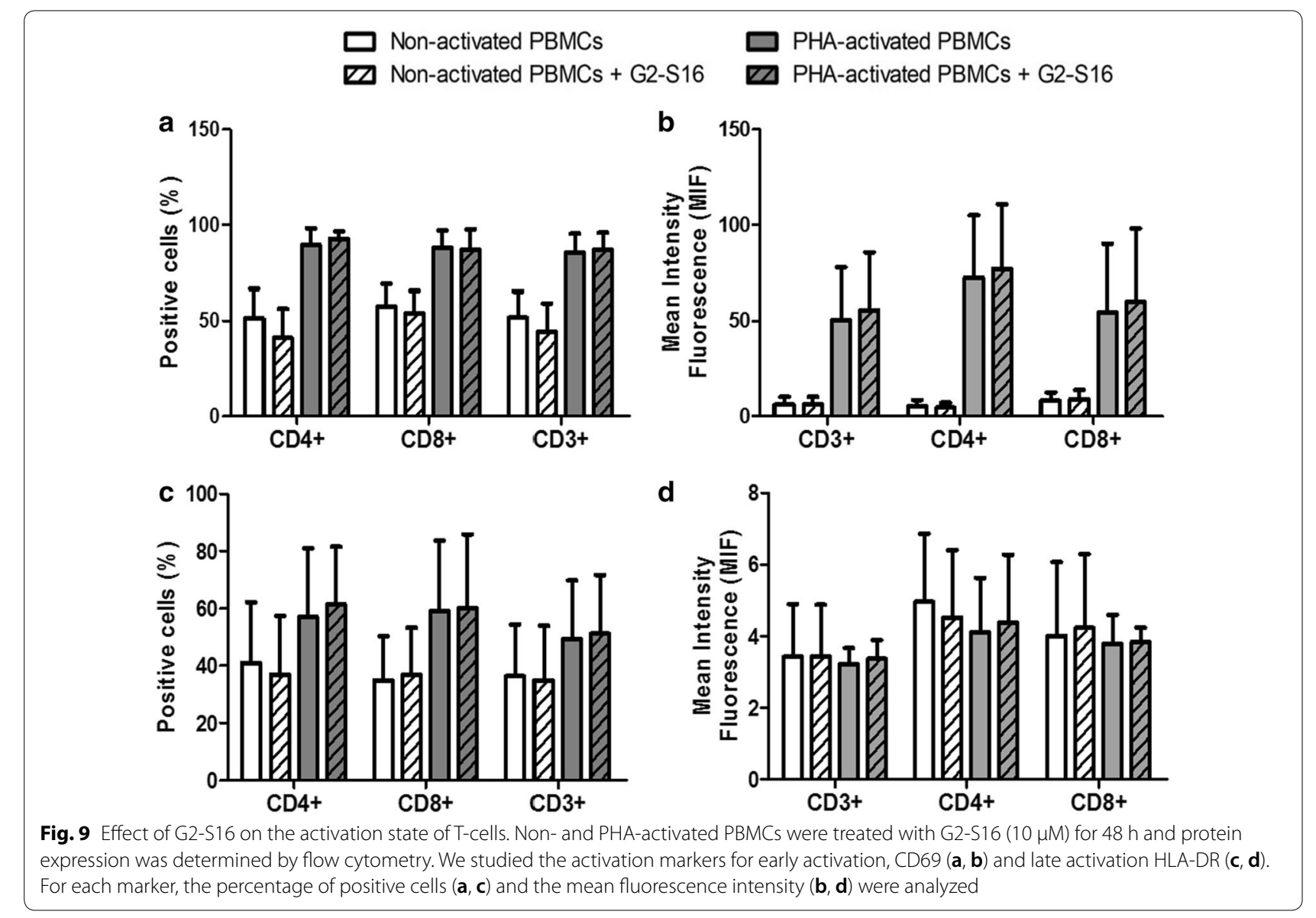

expression of B cell activation markers CD25, CD71, CD86 and HLA-DR by flow cytometry, and found that G2-S16 does not modify the expression of activation markers (Fig. 10b), thus suggesting that it does not affect $B$ cell function.
In summary, the results presented in this study demonstrate that G2-S16 dendrimer does not modify the immune barrier of the FRT, providing stronger evidence of its safety to go to clinical trials as prophylactic treatment against HIV-1 infection. 


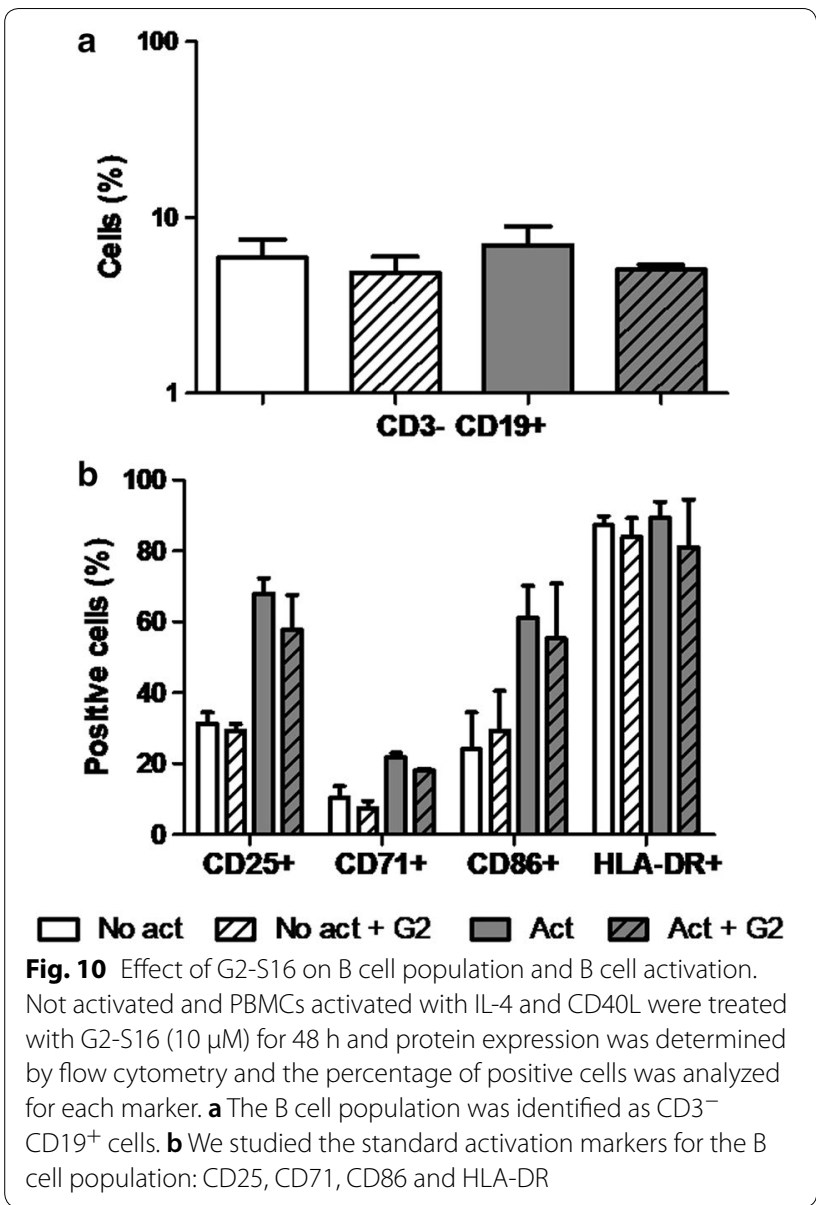

\section{Discussion}

Preventive topical microbicides against HIV-1 infection are designed to be applied in the vagina or rectum and remain there before, during and after sexual intercourse. In the case of HIV-1 exposure, the microbicide should prevent the infection, but it should not interfere with the normal function of the local immune system. This last fact is key for the safety of the compound, but it is frequently overlooked. Many compounds aimed to serve as microbicides fail in clinical trials due to unexpected toxicities or side effects. The objective of this study is to prove the safety of the potential HIV-specific microbicide G2-S16 dendrimer with regards to the vaginal and rectal immunity.

G2-S16 is a second generation of anionic carboxilane dendrimer that has been shown to prevent HIV-1 infection in vitro [19] and in vivo using humanized BLT mice [38]. G2-S16 has been proven to block HIV infection in multiple cell lines and human primary blood cells Chonco et al. [19]. This dendrimer inhibits infection even in the presence of semen, a known infection enhancer [17, 39], as well as the cell-to-cell transmission and syncytium formation [40]. On the other hand, the biosafety of this nanocompound has been tested not only in vitro but also ex vivo and in vivo [19, 20,38]. Cell viability after exposure to G2-S16 remained unaltered for several cell lines and primary cells, including lymphocytes, DCs and MØs. The biocompatibility was also tested in EpiVaginalTM human vaginal epithelial tissue, by MTT assay [20]. Finally, animal models including mice and rabbits were used to assess and confirm the safety of G2-S16 regarding vaginal epithelium irritation and inflammation [20]. These results altogether present G2-S16 as a promising candidate for topical microbicide against HIV-1 infection, situating this dendrimer on the way to clinical trials.

The results presented in our study show that G2-S16 is not only efficient in HIV-1 prevention and safe regarding cell survival, but it also respects the phenotype of the main immune cells exposed. The sexual transmission of the HI-1 can occur through the vagina or the rectus, and the main immune cells exposed to this microbicide will be the innate immune cells in the vaginal mucosa, DCs and $M Ø s$, and the lymphocytes after epithelial damage in the rectum. DCs and MØs are tissue resident cells that differentiate from monocytes. Our study demonstrates that the exposure to G2-S16 does not modify the differentiation of monocytes to either DCs or MØs. DCs patrol the mucosal tissue in the search for pathogens, and upon detection of an antigen, they undergo maturation and migrate towards the lymph nodes, where they activate naive lymphocytes. DC maturation implies the expression of membrane proteins responsible for cell migration (CCR7) or T cell activation (CD80, CD83 and CD86). Our results show that the exposure of differentiated DCs to the dendrimer does not modify the levels of maturation achieved after exposure to an antigen, such as LPS. MØs are divided into two main populations known as M and GM-MØs, which work as tissue-repair cells and pro-inflammatory cells, respectively. Under specific circumstances, the populations can be modified to create a pro-inflammatory or anti-inflammatory environment. However, in order to maintain tissue homeostasis, the equilibrium between both populations is key and any alteration caused by an external treatment, such a prophylactic drug, could have unpredicted and highly damaging consequences. Our results show that MØ-populations exposed to G2-S16 do not suffer any alteration in the ratio of M/GM-MØs.

Differently from what happens in the vagina, in the case of rectal transmission of HIV-1, the first cells infected are the $\mathrm{CD} 4^{+}$lymphocytes from the bloodstream, after the virus crosses the epithelium through micro wounds that occur during sexual intercourse. The prophylactic treatment would be applied in the rectum and similar to what happens with the virus, it 
would get in touch with the immune cells in the bloodstream. Our results show that G2-S16 does not modify the percentage of CD4 or CD8 positive cells, neither in basal state not in PHA-activated PBMCs. In each population, G2-S16 also does not alter the amount of antibody bound, and thus, the amount of protein expressed per cell. These results also discard the option of G2-S16 binding to $\mathrm{CD} 4$ as a mechanism of protection against HIV-1, as the same amount of antibody was able to bind to the treated cells compared to the untreated, thus suggesting that G2-S16 does not block the binding to the virus either. Under the same experimental conditions, these results also showed that the expression of HIV-1 co-receptors CCR5 and CXCR4 remained unchanged after exposure to G2-S16, both when looking at the percentage of cells or the protein expression. Although TLRs are primarily believed to dictate the innate immune response, increasing data is providing evidence of the role of the expression and activation of TLRs in T cells, and thus, the adaptive immune response [35, 36]. Our data clearly show that G2-S16 does not have a significant effect on the expression of TLRs in $\mathrm{CD}^{+} \mathrm{T}$ cells at the time points studied.

Up until this point, our results suggest that G2-S16 does not activate the immune system, as it does not cause any maturation changes in the APCs and does not activate $\mathrm{T}$ cells via TLR signaling either. The evaluation of the expression of the T-cell maturation markers, CD69 and HLA-DR for early and late activation respectively [37], further proved that G2-S16 does not affect the activation of the immune cells in the absence of an exogenous antigen.

These results also discard the option of G2-S16 binding to CD4 as a mechanism of protection against HIV-1, as the same amount of antibody was able to bind to the treated cells compared to the untreated, thus supporting the hypothesis that it binds to the viral surface. G2-S16 dendrimer has been demonstrated to protect against HIV-1 infection when used as prophylactic treatment both in vitro and in vivo, but the mechanism of this protection remains controversial. Computational modeling assays show that it disrupts the union of the virus to the host cell, but they show that it could bind to residues in both the viral gp120 and the CD4 cellular receptor [40]. The cytometry assays performed here show that G2-S16 does not block the binding of antibodies to CD4 receptor, and thus suggest that it does not block the binding of the virus either.

We studied the most likely facts that could be affected by the dendrimer, but other membrane proteins or factors could be altered. Also, it could affect other cell types present in the FRT, including NKs or B cells. Although it is unlikely that the dendrimer could affect these cell types, and we analyzed here the main ways the dendrimer could alter and harm the normal immune function, further studies in this field would be useful to totally grant the non-interaction of G2-S16 dendrimer with the IS.

\section{Conclusions}

Summarizing, in this study we evaluated the effect of G2-S16 dendrimer on the epithelial and immune cells present in the FRT with the aim of identifying potential negative effects prior to clinical trials. These data provide a widen understanding and a more rigorous preclinical tool for the safety evaluation of G2-S16. Our in vitro findings show that G2-S16 dendrimer can slightly interfere with TLR responses on different cell populations, mostly on DCs, but the over-expression of the receptor does not affect the cell functions or the expression of other relevant markers. Epithelial cells, DCs, MØs and lymphocytes, which are the main components of the first barrier of defense in the FRT and rectus are not significantly altered by G2-S16, providing stronger evidence that the dendrimer is safe for clinical use. Further in vitro and in vivo studies would be useful to validate these in vitro results. Additional in vitro assays should include effects on viability of B-cells, target cell recognition by natural killer cells and cell trafficking from the vaginal mucosa.

\section{Materials and methods Reagents}

Water-soluble polyanionic carbosilane dendrimer G2-S16 $\left(\mathrm{C}_{112} \mathrm{H}_{244} \mathrm{~N}_{8} \mathrm{Na}_{16} \mathrm{O}_{48} \mathrm{~S}_{16} \mathrm{Si}_{13} ; \quad \mathrm{Mw}=3717.15 \mathrm{~g} /\right.$ mol) was synthesized according to methods reported by the University of Alcalá [41]. G2-S16 consists of a second-generation dendrimer scaffold built from a silicon atom core and fully capped on the surface with 16 sulfonate groups. The second-generation was defined taking into account the number of repeated layers of silicon atoms forming the dendrimer. A $10 \mathrm{mM}$ stock solution of G2-S16 and subsequent dilutions to obtain $\mu \mathrm{M}$ concentrations were prepared in nuclease-free water (Promega, Madison, WI, USA).

\section{Cell line culture}

Vaginal epithelium VK2/E6E7 cells (ATCC ${ }^{\circledR}$ CRL-2616 ${ }^{\mathrm{TM}}$, Manassas, VA, USA) were seeded at $0.25 \times 10^{6}$ cells $/ \mathrm{mL}$ and cultured in keratinocyte serum-free medium (Gibco, Paisley, UK) with $0.1 \mathrm{ng} / \mathrm{mL}$ human recombinant epidermal growth factor (hrEGF; Immunotools, Friesoythe, Germany), $0.05 \mathrm{mg} / \mathrm{mL}$ bovine pituitary extract (BPE; Sigma-Aldrich, St. Louis, MO, USA) and calcium chloride (Sigma) at $0.4 \mathrm{mM}$. 


\section{Primary cell cultures, purification and differentiation}

Human peripheral blood mononuclear cells (PBMCs) were isolated from buffy coats obtained from anonymized healthy blood donors coming from the transfusion Center of Madrid following national guidelines. PBMCs were isolated by a standard Ficoll-Hypaque density gradient (Rafer, Madrid, Spain) and cultured following the procedures of Spanish HIV HGM BioBank [42-45]. PBMCs were kept with $60 \mathrm{U} / \mathrm{mL}$ of interleukin 2 (IL-2; Bachem AG, Bubendorf, Switzerland) and stimulated with $60 \mathrm{U} / \mathrm{mL}$ of interleukin 2 (IL-2; Bachem AG, Bubendorf, Switzerland) and $2 \mu \mathrm{g} / \mathrm{mL}$ of phytohemaglutinin (PHA; Remel, Santa Fe, NM, USA) for $48 \mathrm{~h}$ before the experiments for $\mathrm{T}$ cell analysis. For B cell studies, PBMCs were stimulated with $50 \mathrm{ng} / \mathrm{mL}$ interleukin 4 (rhIL-4; Immunotools) and $500 \mathrm{ng} / \mathrm{mL}$ CD40 ligand (CD40L, Invitrogen).

CD4-T cells were purified from PBMCs using immunomagnetic anti-CD4 microbeads (CD4 MicroBeads; Miltenyi Biotec, Bergisch Gladbach, Germany). Purified CD4-T cells were seeded at $5 \times 10^{6}$ cells $/ \mathrm{mL}$ in RPMI1640 medium (Biochrom AG, Berlin, Germany) with $10 \%$ fetal bovine serum (FBS; Gibco), 1\% L-glutamine (Lonza, Walkersville, MD, USA), antibiotic cocktail $(125 \mathrm{mg} / \mathrm{mL}$ ampicillin, $125 \mathrm{mg} / \mathrm{mL}$ cloxacillin and $40 \mathrm{mg} / \mathrm{mL}$ gentamicin; all from Normon, Madrid, Spain) and $60 \mathrm{U} / \mathrm{mL}$ of IL-2.

Monocytes were purified using immune-magnetic antiCD14 microbeads (Miltenyi) and were seeded under different conditions depending on the cell type to which would differentiate.

Immature DCs (iDCs) and mature DCs (mDCs): Monocytes were seeded at $10^{6}$ cells $/ \mathrm{mL}$ in RPMI-1640 medium supplemented with $10 \% \mathrm{FBS}, 1 \%$ L-glutamine, $50 \mu \mathrm{M} \beta$-2-mercaptoethanol (Sigma), $20 \mathrm{ng} / \mathrm{mL}$ recombinant human interleukin 4 (rhIL-4; Immunotools) and $50 \mathrm{ng} / \mathrm{mL}$ recombinant human granulocyte macrophage colony stimulating factor (rh GM-CSF; Immunotools), and were maintained during 5 days. Culture medium was renewed the $3 r d$ day. iDCs were cultured for $48 \mathrm{~h}$ in the presence of lipopolysaccharide (LPS; Sigma) at $20 \mathrm{ng} / \mathrm{mL}$ to stimulate maturation.

GM-MØs: Monocytes were cultured at $0.5 \times 10^{6}$ cells/ $\mathrm{mL}$ for 7 days in RPMI-1640 medium supplemented with $10 \% \mathrm{FBS} ; 1 \% \mathrm{~L}$-glutamine and $10 \mathrm{ng} / \mathrm{mL}$ of rhGM-CSF to generate GM-MØs. Cytokines were added every 2 days.

M-MØs: Monocytes were cultured at $0.5 \times 10^{6}$ cells/ $\mathrm{mL}$ for 7 days in RPMI-1640 medium supplemented with $10 \%$ FBS, $1 \%$ L-glutamine and $10 \mathrm{ng} / \mathrm{mL}$ of recombinant human macrophage-colony stimulating factor (rhMCSF; Immunotools) to generate M-MØs. Cytokines were added every 2 days.

\section{Cell viability assay}

The tetrazolium dye colorimetric assay is a method for testing cell cytotoxic activity in vitro. The 3-(4,5-dimethylthiazol-2-yl)-2,5-diphenyl-tetrazolium-bromide (MTT; Sigma) was used following the manufacturer's instructions to determine the viability of DCs and MØs (cell density of $7.5 \times 10^{4}$ and $5 \times 10^{4}$ cells $/ \mathrm{mL}$, respectively) in the presence of G2-S16 dendrimer or controls.

\section{Flow cytometry}

Analysis of cell-surface phenotype of DCs and MØs was performed by flow cytometry. Cells were labeled with anti-CD4-FITC, anti-CD69-PC5, anti-CD80-FITC, anti-CD1a-PE, anti-HLA-DR-ECD, anti-CD14-PC7, anti-CD86-PC5.5 (all from Beckman Coulter Inc., Brea, CA, USA), anti-CD8-Pacific Blue, anti-CD36-APC, anti-CD197-APC-Cy7 (CCR7) (all from BioLegend, San Diego, CA, USA), anti-CCR5-PE, anti-CD209-PE, antiCD83-APC (all from BD Biosciences, Franklin Lake, NJ, USA), anti-CXCR4-APC (RandD systems, Minneapolis, $\mathrm{MN}, \mathrm{USA})$ and anti-CD163-FITC (MBL International Corp., Woburn, WA, USA). Levels of surface expression on cells were estimated by flow cytometry (Gallios; Beckman) and analyzed using Kaluza software (Beckman).

\section{Treatment of cell cultures for RNA extraction}

After cells were purified and/or differentiated, and seeded at appropriate conditions (indicated above), were treated with G2-S16 at the highest non-toxic dose considering the cell line evaluated in this study or previously reported $[18,19]$. In adherent culture cells, after $3 \mathrm{~h}, 6 \mathrm{~h}$ and $18 \mathrm{~h}$ of treatment, the supernatants were removed and cells were washed once with phosphate-buffered saline (PBS; Lonza), then the RNA extraction was performed. In suspension cultures, after $3 \mathrm{~h}, 6 \mathrm{~h}$ and $18 \mathrm{~h}$ of treatment, the cells were placed in a tube and centrifuged at $600 \times g$ for $10 \mathrm{~min}$, supernatants were removed and pellet were washed once with PBS, then, centrifuged at $600 \times g$ for $10 \mathrm{~min}$ and the pellet was used to perform the cellular RNA extraction.

\section{RNA extraction and TLR mRNA expression detection by RT-qPCR}

RNA of all samples (adherent cells or pellet cells) was extracted using the RNeasy Plus mini kit (Qiagen, Valencia, CA, USA) and RNA integrity was analyzed with Agilent 2100 bioanalyzer (Agilent Technologies, Palo Alto, CA, USA) by using RNA Nano chips (Agilent). To perform the process of reverse transcription, a reverse transcriptase was used to generate complementary DNA (cDNA) from RNA templates with the GoScript Reverse Transcription System (Promega). mRNA expression was analyzed by quantitative real-time PCR 
using specific probes and primers (see Table 1) for TLR1, TLR2, TLR3, TLR4, TLR5, TLR6, TLR7, TLR8, TLR9 and TLR10 designed by using the Universal Human Probe Roche library system (Roche Diagnostics, Basel, Switzerland). Results were processed with the Bio-Rad iQ5 2.0 software (Hercules, CA, USA). Data was normalized according to the expression levels of TATA-binding protein (TBP) mRNA, used as a housekeeping gene, and expressed the fold change relative to the mRNA level of untreated samples (value $=1$ ). The 1.5 and 0.5 folds change were established as threshold values.

\section{Acknowledgements}

We acknowledge the Spanish HIV HGM BioBank integrated in the Spanish AIDS Research Network and the National Network BioBank and supported by the Instituto Salud Carlos III for helping to isolate the PBMCs. We acknowledge Dr. Francisco Javier de la Mata and Dr. Rafael Gomez for synthesizing the G2-S16 dendrimer.

\section{Authors' contributions}

MMF conceived, designed, planned, discussed and directed the experiments. AM designed, planned and performed the experiments. MS, JP designed and performed experiments. DS analyzed data and revised the manuscript. MMF and AM analyzed data and wrote the manuscript. All authors read and approved the final manuscript.

\section{Funding}

This work has been (partially) funded by the RD16/0025/0019, projects as part of Acción Estratégica en Salud, Plan Nacional de Investigación Científica, Desarrollo e Innovación Tecnológica (2013-2016) and cofinanced by Instituto de Salud Carlos III (Subdirección General de Evaluación) and Fondo Europeo de Desarrollo Regional (FEDER), RETIC PT17/0015/0042, Fondo de Investigacion Sanitaria (FIS) (Grant Number PI16/01863) and EPIICAL Project. This work has been supported by Faculty of Biology and Environmental Protection for interdisciplinary research and innovation of the University of Lodz: NAWA International Academic Partnership Programme. This article/publication is based upon work from COST Action CA17140"Cancer Nanomedicine from the Bench to the Bedside" supported by COST (European Cooperation in Science and Technology). CIBER-BBN as an initiative funded by VI National R-D-i Plan 2008-2011, Iniciativa Ingenio 2010, Consolider Program, CIBER Actions and financed by the Instituto de Salud Carlos III with assistance from the European Regional Development Fund. A.M. acknown Ministerio de Economía y Competitividad for a predoctoral fellowship. Grants from CTQ2017-86224-P (MINECO), Consortiums NANODENDMED II-CM ref B2017/BMD-3703 and IMMUNOTHERCAN-CM B2017/BMD-3733 (CAM) to UAH.

\section{Availability of data and materials}

All the reagents will be made available to other researcher upon previous request.

\section{Ethics approval and consent to participate}

I declare that no ethical approval or consent to participate is required for this manuscript since the experiment have been performed in PBMC that have been obtained for anonymous buffy coats.

\section{Consent for publication}

All the authors have agreed on the final version of the submitted manuscript.

\section{Competing interests}

The authors declare that they have no competing interests.

\section{Author details}

${ }^{1}$ Sección Inmunología, Laboratorio InmunoBiología Molecular, Hospital General Universitario Gregorio Marañón (HGUGM), Instituto de Investigación Sanitaria Gregorio Marañón (IiSGM), and Spanish HIV-HGM BioBank, Madrid,
Spain. ${ }^{2}$ Networking Research Center on Bioengineering, Biomaterials and Nanomedicine (CIBER-BBN), Madrid, Spain.

Received: 8 January 2019 Accepted: 4 May 2019

Published online: 15 May 2019

\section{References}

1. Notario-Perez F, Ruiz-Caro R, Veiga-Ochoa MD. Historical development of vaginal microbicides to prevent sexual transmission of HIV in women: from past failures to future hopes. Drug Des Dev Ther. 2017;11:1767-87.

2. Coutinho C, Sarmento B, das Neves J. Targeted microbicides for preventing sexual HIV transmission. J Control Release. 2017;266:119-28.

3. Amjadi F, Salehi E, Mehdizadeh M, Aflatoonian R. Role of the innate immunity in female reproductive tract. Adv Biomed Res. 2014;3:1.

4. Sheldon IM, Owens SE, Turner ML. Innate immunity and the sensing of infection, damage and danger in the female genital tract. J Reprod Immunol. 2017;119:67-73.

5. Kaushic C. HIV-1 infection in the female reproductive tract: role of interactions between HIV-1 and genital epithelial cells. Am J Reprod Immunol. 2011;65(3):253-60.

6. Lavelle EC, Murphy C, O'Neill LA, Creagh EM. The role of TLRs, NLRs, and RLRs in mucosal innate immunity and homeostasis. Mucosal Immunol. 2010;3(1):17-28.

7. McClure R, Massari P.TLR-dependent human mucosal epithelial cell responses to microbial pathogens. Front Immunol. 2014;5:386.

8. Nasu K, Narahara H. Pattern recognition via the toll-like receptor system in the human female genital tract. Mediat Inflamm. 2010;2010:976024.

9. Anthoney N, Foldi I, Hidalgo A. Toll and toll-like receptor signalling in development. Development. 2018. https://doi.org/10.1242/dev.156018.

10. Vijay K. Toll-like receptors in immunity and inflammatory diseases: past, present, and future. Int Immunopharmacol. 2018;59:391-412.

11. Thompson MR, Kaminski JJ, Kurt-Jones EA, Fitzgerald KA. Pattern recognition receptors and the innate immune response to viral infection. Viruses. 2011;3(6):920-40

12. Sattentau QJ, Stevenson M. Macrophages and HIV-1: an unhealthy constellation. Cell Host Microbe. 2016;19(3):304-10.

13. Atri C, Guerfali FZ, Laouini D. Role of human macrophage polarization in inflammation during infectious diseases. Int J Mol Sci. 2018;19(6):1801.

14. das Neves J, Nunes R, Rodrigues F, Sarmento B. Nanomedicine in the development of anti-HIV microbicides. Adv Drug Deliv Rev. 2016;103:57-75.

15. Brako F, Mahalingam S, Rami-Abraham B, Craig DQ, Edirisinghe M. Application of nanotechnology for the development of microbicides. Nanotechnology. 2017;28(5):052001.

16. Cena-Diez R, Vacas-Cordoba E, Garcia-Broncano P, de la Mata FJ, Gomez R, Maly $M$, et al. Prevention of vaginal and rectal herpes simplex virus type 2 transmission in mice: mechanism of antiviral action. Int J Nanomed. 2016:11:2147-62.

17. Cena-Diez R, Garcia-Broncano P, de la Mata FJ, Gomez R, Munoz-Fernandez MA. Efficacy of HIV antiviral polyanionic carbosilane dendrimer G2-S16 in the presence of semen. Int J Nanomed. 2016;11:2443-50.

18. Briz V, Sepulveda-Crespo D, Diniz AR, Borrego P, Rodes B, de la Mata FJ, et al. Development of water-soluble polyanionic carbosilane dendrimers as novel and highly potent topical anti-HIV-2 microbicides. Nanoscale. 2015;7(35):14669-83.

19. Chonco L, Pion M, Vacas E, Rasines B, Maly M, Serramia MJ, et al. Carbosilane dendrimer nanotechnology outlines of the broad HIV blocker profile. J Control Release. 2012;161(3):949-58.

20. Cena-Diez R, Garcia-Broncano P, Javier de la Mata F, Gomez R, Resino S, Munoz-Fernandez M. G2-S16 dendrimer as a candidate for a microbicide to prevent HIV-1 infection in women. Nanoscale. 2017;9(27):9732-42.

21. Jaramillo-Ruiz D, De La Mata FJ, Gomez R, Correa-Rocha R, Munoz-Fernandez MA. Nanotechnology as a new therapeutic approach to prevent the HIV-infection of treg cells. PLoS ONE. 2016;11(1):e0145760.

22. Nazli A, Kafka JK, Ferreira VH, Anipindi V, Mueller K, Osborne BJ, et al. HIV-1 gp120 induces TLR2- and TLR4-mediated innate immune activation in human female genital epithelium. J Immunol. 2013;191(8):4246-58. 
23. Chandran SS, Verhoeven D, Teijaro JR, Fenton MJ, Farber DL. TLR2 engagement on dendritic cells promotes high frequency effector and memory CD4 T cell responses. J Immunol. 2009;183(12):7832-41.

24. Re F, Strominger JL. Toll-like receptor 2 (TLR2) and TLR4 differentially activate human dendritic cells. J Biol Chem. 2001;276(40):37692-9.

25. Thoma-Uszynski S, Kiertscher SM, Ochoa MT, Bouis DA, Norgard MV, Miyake K, et al. Activation of toll-like receptor 2 on human dendritic cells triggers induction of IL-12, but not IL-10. J Immunol. 2000;165(7):3804-10.

26. Manches $\mathrm{O}$, Frleta D, Bhardwaj N. Dendritic cells in progression and pathology of HIV infection. Trends Immunol. 2014;35(3):114-22.

27. Brigl M, Brenner MB. CD1: antigen presentation and T cell function. Annu Rev Immunol. 2004;22:817-90.

28. Albert ML, Jegathesan $M$, Darnell RB. Dendritic cell maturation is required for the cross-tolerization of CD8 ${ }^{+} T$ cells. Nat Immunol. 2001;2(11):1010-7.

29. Forster R, Schubel A, Breitfeld D, Kremmer E, Renner-Muller I, Wolf E, et al. CCR34 coordinates the primary immune response by establishing functional microenvironments in secondary lymphoid organs. Cell. 1999;99(1):23-33.

30. Cassol E, Cassetta L, Alfano M, Poli G. Macrophage polarization and HIV-1 infection. J Leukoc Biol. 2010;87(4):599-608.

31. Lugo-Villarino G, Verollet C, Maridonneau-Parini I, Neyrolles O. Macrophage polarization: convergence point targeted by mycobacterium tuberculosis and HIV. Front Immunol. 2011;2:43.

32. Oh J, Riek AE, Weng S, Petty M, Kim D, Colonna M, et al. Endoplasmic reticulum stress controls $\mathrm{M} 2$ macrophage differentiation and foam cell formation. J Biol Chem. 2012;287(15):11629-41.

33. Bouhlel MA, Derudas B, Rigamonti E, Dievart R, Brozek J, Haulon S, et al. PPARgamma activation primes human monocytes into alternative M2 macrophages with anti-inflammatory properties. Cell Metab. 2007;6(2):137-43.

34. Tarique AA, Logan J, Thomas E, Holt PG, Sly PD, Fantino E. Phenotypic, functional, and plasticity features of classical and alternatively activated human macrophages. Am J Respir Cell Mol Biol. 2015;53(5):676-88.

35. MacLeod H, Wetzler LM. T cell activation by TLRs: a role for TLRs in the adaptive immune response. Sci STKE. 2007;2007(402):pe48.

36. Gelman AE, Zhang J, Choi Y, Turka LA. Toll-like receptor ligands directly promote activated CD4 ${ }^{+}$T cell survival. J Immunol. 2004;172(10):6065-73.
37. Lichtfuss GF, Hoy J, Rajasuriar R, Kramski M, Crowe SM, Lewin SR. Biomarkers of immune dysfunction following combination antiretroviral therapy for HIV infection. Biomark Med. 2011;5(2):171-86.

38. Sepulveda-Crespo D, Serramia MJ, Tager AM, Vrbanac V, Gomez R, De La Mata FJ, et al. Prevention vaginally of HIV-1 transmission in humanized BLT mice and mode of antiviral action of polyanionic carbosilane dendrimer G2-S16. Nanomedicine. 2015;11(6):1299-308.

39. Garcia-Broncano P, Cena-Diez R, de la Mata FJ, Gomez R, Resino S, MunozFernandez MA. Efficacy of carbosilane dendrimers with an antiretroviral combination against HIV-1 in the presence of semen-derived enhancer of viral infection. Eur J Pharmacol. 2017;811:155-63.

40. Guerrero-Beltran C, Rodriguez-Izquierdo I, Serramia MJ, Araya-Duran I, Marquez-Miranda V, Gomez R, et al. Anionic carbosilane dendrimers destabilize the GP120-CD4 complex blocking HIV-1 entry and cell to cell fusion. Bioconjug Chem. 2018;29(5):1584-94.

41. Rasines B, Sanchez-Nieves J, Maiolo M, Maly M, Chonco L, Jimenez JL, et al. Synthesis, structure and molecular modelling of anionic carbosilane dendrimers. Dalton Trans. 2012;41(41):12733-48.

42. Consuegra I, Rodriguez-Aierbe C, Santiuste I, Bosch A, Martinez-Marin $\mathrm{R}$, Fortuto MA, et al. Isolation methods of peripheral blood mononuclear cells in Spanish Biobanks: an overview. Biopreserv Biobank. 2017;15(4):305-9.

43. Garcia-Merino I, de Las Cuevas N, Jimenez JL, Garcia A, Gallego J, Gomez C, et al. Pediatric HIV BioBank: a new role of the Spanish HIV BioBank in pediatric HIV research. AIDS Res Hum Retroviruses. 2010;26(2):241-4.

44. Garcia-Merino I, de Las Cuevas N, Jimenez JL, Gallego J, Gomez C, Prieto C, et al. The Spanish HIV BioBank: a model of cooperative HIV research. Retrovirology. 2009;6:27.

45. Garcia-Merino IM, Consuegra I, Jimenez JL, Munoz-Fernandez MA. Specific legislation on biobanks in Spain. Biopreserv Biobank. 2015;13(3):207-11.

\section{Publisher's Note}

Springer Nature remains neutral with regard to jurisdictional claims in published maps and institutional affiliations.
Ready to submit your research? Choose BMC and benefit from:

- fast, convenient online submission

- thorough peer review by experienced researchers in your field

- rapid publication on acceptance

- support for research data, including large and complex data types

- gold Open Access which fosters wider collaboration and increased citations

- maximum visibility for your research: over $100 \mathrm{M}$ website views per year

At BMC, research is always in progress.

Learn more biomedcentral.com/submissions 